\title{
Caracterização Fisiográfica e do uso e Ocupação do Solo das Microbacias Urbanas da Cidade de Cuiabá-MT
}

\section{Physiographic Characterization and Land use and Occupation of the Urban Microbasins of the City of Cuiabá-MT}

${ }^{1}$ Gabriel Figueiredo de Moraes 1, ${ }^{2}$ Eliana Beatriz Nunes Rondon Lima 2, ${ }^{3}$ Elisangela Maria Ferrarez,

${ }^{1}$ Engenheiro Sanitarista e Ambiental, mestrando do programa de Pós-graduação em Engenharia de Edificações e Ambiental da Faculdade de Arquitetura, Engenharia e Tecnologia, Universidade Federal de Mato Grosso,

Av. Fernando Correa da Costa, 2367, FAET, Cuiabá-MT, (gabrielmoraes@ufmt.br) ${ }^{2}$ Doutora em Engenharia Civil, Professor Adjunta da Faculdade de Arquitetura, Engenharia e Tecnologia, Universidade Federal de Mato Grosso, Av. Fernando Correa da Costa, 2367, FAET, Cuiabá-MT,

(elianar@ufmt.br)

${ }^{3}$ Engenheira Sanitarista e Ambiental, aluna especial programa de Pós-graduação em Engenharia de Edificações e Ambiental da Faculdade de Arquitetura, Engenharia e Tecnologia, Universidade Federal de Mato Grosso, Av. Fernando Correa da Costa, 2367, FAET, Cuiabá-MT (emferrarez@ gmail.com)

\begin{abstract}
RESUMO: O processo de urbanização brasileira ocorreu de maneira intensa e rápida, tendo como resultado a degradação dos serviços ecológicos. O uso e manejo inadequados do espaço urbano e a falta de ações conservacionistas propiciam perdas significativas, assim, o levantamento do uso e cobertura da terra é a primeira etapa para o planejamento conservacionista. Estudos que pretendam diagnosticar as condições do ambiente natural e avaliar sua dinâmica, podem contribuir para a gestão sustentável da bacia hidrográfica. Nessa perspectiva, o presente trabalho tem por objetivo geral realizar a delimitação das bacias hidrográficas localizadas na área urbana do munícipio de Cuiabá-MT e a caracterização fisiográfica e diagnóstico do uso e ocupação do solo, por meio de uso de imagens de satélite. Para este estudo, foram consideradas três etapas metodológicas, sendo i) caracterização da área e bacias de estudo; ii) levantamento e caracterização da base de dados e iii) determinação das características fisiográficas. Para tanto, utilizou-se a ferramenta ArcHydros e o software ArcGis na versão 10.5 e o software ecognitiondevelope 64. As imagens de satélite foram retiradas do LANDSAT 08 (L8-OLI). Os resultados apontam que a microbacia do córrego Mané Pinto apresenta maiores valores de fato forma, índice de circularidade e faixa densa de ocupação urbana entre 80 a 90\%, caracterizando ausência de mata ciliar. Já o Rio Coxipó apresenta menores valores de fator forma e índice de circularidade, porém apresenta valores superiores a $40 \%$ de vegetação rasteira.
\end{abstract}

Palavras Chave: Planejamento urbano. Hidrologia. Sistema de informação geográfica.

ABSTRACT:The Brazilian urbanization process occurred intensely and rapidly, resulting in the degradation of ecological services. The inadequate use and management of urban space and the lack of conservation actions lead to significant losses, so the survey of land use and land cover is the first step in conservation planning. Studies that intend to diagnose the conditions of the natural environment and evaluate their dynamics can contribute to the sustainable management of the river basin. In this perspective, the main objective of this work is to delineate the hydrographic basins located in the urban area of Cuiabá City-MT and the physiographic and diagnostic characterization of the use and occupation of the soil through the use of satellite images. For this study, three methodological steps were considered: i) characterization of the study area and basins; ii) survey and characterization of the database and iii) determination of physiographic characteristics. For this purpose, the Arc Hydros tool and the ArcGis software in version 10.5 and the ecognitiondevelope 64 software were used. The satellite images were taken from LANDSAT 08 (L8-OLI). The results indicate that the microbasin of the Mané Pinto stream presents higher values of fact shape, circularity index and dense range of urban occupation between 80 and $90 \%$, characterizing the absence of ciliary forest. However, the Coxipó River presents lower values of form factor and circularity index, but presents values greater than $40 \%$ of undergrowth.

Keywords: Urban planning. Hydrology. Geographic Information System.

\section{INTRODUÇÃ̃O}

O processo de urbanização brasileira ocorreu de maneira intensa e rápida, com as atividades humanas impulsionadas por fatores socioeconômicos os quais na grande maioria das vezes foram responsáveis pela degradação dos serviços ecológicos. Em decorrência disso, 
as transformações quantitativas resultaram em transformações qualitativas profundas, afetando a qualidade do espaço urbano devido à falta de infraestrutura (TUCCI, 2007). Como consequência, tem-se a necessidade de enfrentar desafios quanto às políticas públicas, à gestão e à organização do território, requerendo soluções articuladas de planejamento e gestão urbanos (HONDA et al., 2015).

É nas áreas urbanas que a ocupação e a concentração humana ocorrem de forma intensa e muitas vezes desordenada. Estes locais são alvos de frequentes desmatamento, deslizamento, erosão, assoreamento dos canais fluviais, e sofrem ainda com fatores como poluição doméstica, industrial, altas taxas de escoamento superficial, ocupação irregular das Áreas de Proteção Permanente (APPs), o que ameaça a disponibilidade e qualidade da água (GUERRA e GONÇALVES, 2001; LIMA, 2013).

O uso e manejo inadequados do espaço urbano e a falta de ações conservacionistas propiciam perdas significativas de solo, de matéria orgânica, nutrientes, da biodiversidade e perdas com enchentes e, em especial, de água, ocasionando prejuízos ao equilíbrio dos sistemas hídricos em bacias hidrográficas. Vaeza et al. (2010) salientam que o levantamento do uso e cobertura da terra como parte de um diagnóstico ambiental é a primeira etapa para o planejamento conservacionista.

Nesse sentido, o disciplinamento do uso e ocupação do solo tem como objetivo assegurar a qualidade e a quantidade dos recursos hídricos de uma bacia hidrográfica, sendo de suma importância para a organização e o desenvolvimento de uma bacia e, concomitantemente, proteção dos recursos naturais (MOTA, 2008).

No Brasil, a bacia hidrográfica é adotada como unidade de estudo, planejamento e gerenciamento dos recursos hídricos, assim como de desenvolvimento econômico e social, conforme estabelece a Lei Federal $\mathrm{n}^{\circ}$ 9.433/97, a Política Nacional de Recursos Hídricos (PNRH) (BRASIL, 1997). Dessa forma, é na bacia hidrográfica que se aplicam os instrumentos da PNRH, tais como: enquadramento dos corpos d'água, outorga e cobrança pelo uso de recursos hídricos.

Medeiros, São Miguel e Brugnolli (2014) indicam que, estudos integrados que pretendam diagnosticar as condições do ambiente natural e avaliar a dinâmica no ambiente, podem contribuir significativamente para a gestão sustentável da bacia hidrográfica. Colet (2012) ressalta que a realização desses estudos fornece subsídios para a elaboração de propostas que visam à sua recuperação e preservação.

Assim, conhecer as características físicas (área, perímetro, forma, rede de drenagem e características de relevo), são condições básicas para o gerenciamento adequado de uma bacia hidrográfica. Villela e Matos (1975) apontam que esses elementos são de grande relevância pratica, pois possibilitam o conhecimento da variação no espaço dos elementos do regime hidrológico. Moreira e Silva (2010) também destacam que essa constitui informação básica para a tomada de decisão em diversos estudos, como processos de outorga, dimensionamentos de obras hidráulicas e planejamentos agrícolas, tornando viável a proposição de medidas apropriadas de uso e ocupação da terra, reduzindo os impactos sobre o ambiente.

Para a determinação dessas características tem-se utilizado ferramentas que auxiliam o processo de delimitação automática de bacias, implementadas em ambientes de Sistemas de Informação Geográfica (SIG). No processo de delimitação automática via SIG de bacias são necessárias informações do relevo, em forma de Modelo Digital de elevação (MDE), o qual é necessário para gerar o Modelo Numérico do Terreno (MNT). Os fenômenos hidrológicos constituem uma característica natural que estão diretamente relacionados com os parâmetros físicos da bacia. Essas características podem interferir, por exemplo, no escoamento 
superficial, o qual é responsável pela interação terra-água e, portanto, nos processos erosivos, no transporte de poluentes até os corpos d'água, nos tipos de uso e ocupação que se faz da terra, dentre outros (PRADO et al., 2010).

$\mathrm{Na}$ aquisição de dados físicos presentes em bacias hidrográficas, as geotecnologias têm sido as mais utilizadas, visto que, as mesmas possibilitam uma avaliação integrada dos sistemas naturais e garantem a otimização nos estudos dos recursos naturais, pois há maior facilidade na aquisição dos dados (SOUZA et al., 2013).

Diante do exposto, objetiva-se caracterizar fisiograficamente e diagnosticar o uso e ocupação do solo de bacias hidrográficas localizadas na área urbana do município de CuiabáMT por meio de imagens de satélite. A contribuição deste trabalho é gerar informações físiográficas sobre o uso e ocupação do solo dentro das bacias hidrográficas pesquisadas, de tal forma que estas auxiliem os planejadores na tomada de decisões quanto ao desenvolvimento econômico e social destas bacias, mas também quanto a proteção dos recursos naturais nela existentes.

\section{MATERIAIS E MÉTODOS}

\subsection{Caracterização da área de estudo}

A área de estudo compreende as bacias hidrográficas das oito principais Rios e Córregos circunscritos no município de Cuiabá-MT e que fazem parte da drenagem hidrográfica na zona urbana, sendo elas: a bacia do Rio Coxipó, bacia do Rio Ribeirão do Lipa, bacia do Córrego Mané Pinto, bacia do Córrego do Gambá, bacia do Córrego São Gonçalo, bacia do Córrego da Prainha, bacia do Córrego Lavrinha e bacia do Córrego Barbado, todas afluentes do Rio Cuiabá. Todas as nascentes encontram-se dentro do munícipio, com exceção do Rio Coxipó, onde sua nascente encontra-se ao município de Chapada dos Guimarães (Figura 1).

Figura 1 - Localização da área de estudo

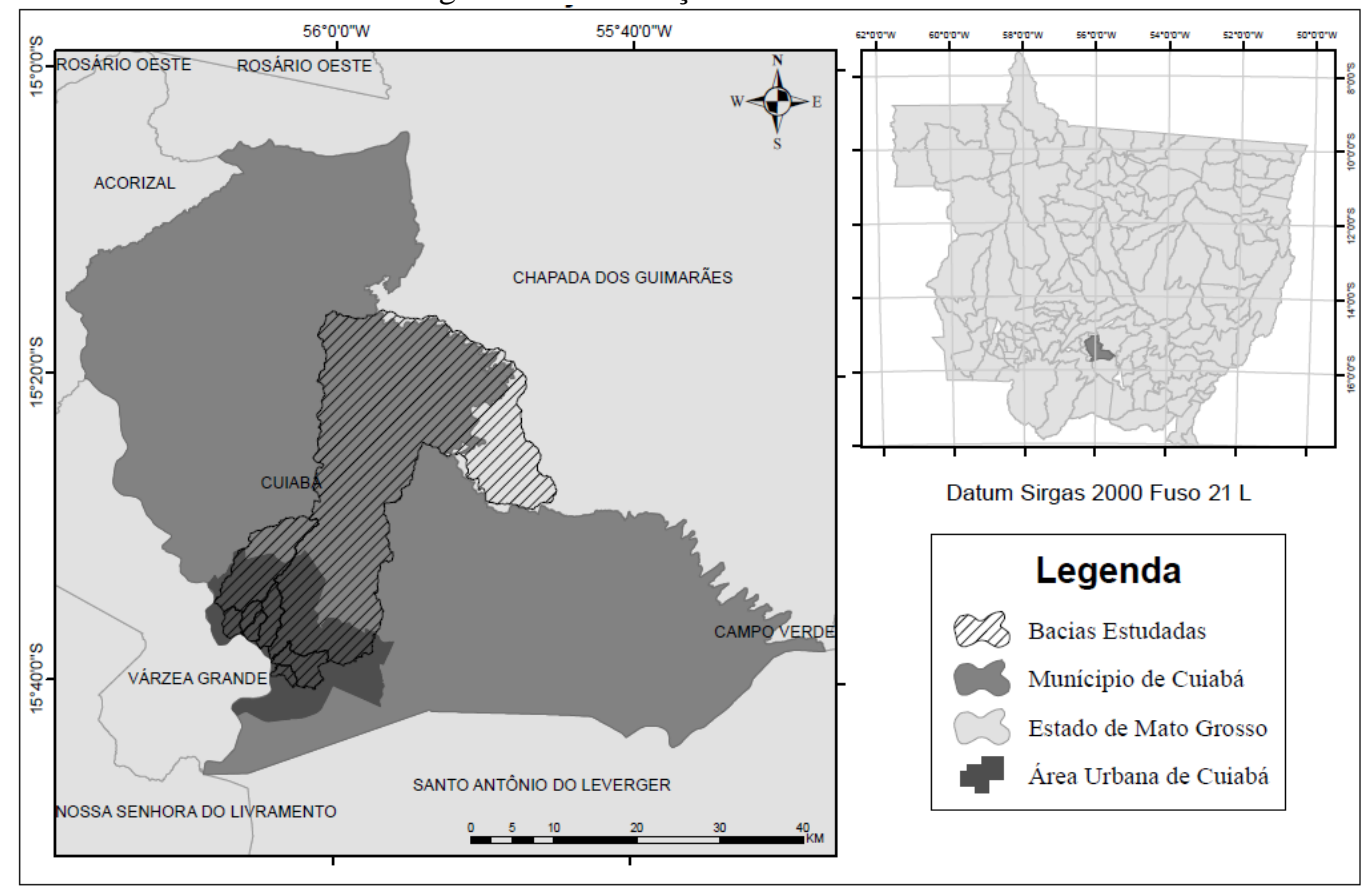

Fonte: Os autores 
Destaca-se que, $66,76 \%$ da área urbana do município é ocupada por essas bacias, cuja está localizada as margens esquerda do Rio Cuiabá $\left(15^{\circ} \mathrm{S} ;-56^{\circ} \mathrm{O}\right)$ fazendo divisa com o município de Várzea Grande-MT.

\subsection{Base de dados}

A elaboração deste trabalho utilizou como base a derivação altitude da folha 15S57 do Modelo Digital de Elevação (MDE), extraídos do Banco de Dado Geomorfométricos do Brasil (TOPODATA) do Instituto Nacional de Pesquisas Espaciais - INPE (BRASIL, 2018). As delimitações das bacias hidrográficas foram geradas automaticamente, por meio da extensão ArcHydro, suas fisiografias e os mapas de declividade foram geradas no software ArcGIS®10.5.

A segmentação e classificação das imagens foram realizadas por meio do software eCognitionDeveloper 64 e a tabulação dos dados foi realizada com o auxílio de planilhas do MS EXCEL. As imagens utilizadas para a classificação do uso e ocupação das bacias foram extraídas da folha 226/071, imageada pelo satélite LANDSAT 08 (L8-OLI) no dia 24 de maio de 2017, no catalogo de imagens do INPE/DGI. A folha possui um percentual de nuvens de 0,04\%, garantindo a possibilidade de gerar uma classificação das feições existentes na imagem com baixo comprometimento nos resultados.

O processo de delimitação automática das bacias foi desenvolvido pela extensão ArcHydro na plataforma ArcMap, para isso utilizou-se a folha $15 \mathrm{~S} 7$ do MDE TOPODATADA. Para que a extensão ArcHydro executasse o procedimento, o MDE foi ajustado com os Pixels Type UNSIGNED INTEGER e Pixels Depth 16 Bit com referência inicial em WGS1984 e resolução espacial de $30 \mathrm{~m}$. Posteriormente o MDE foi reprojetado para o Datum-Sistema de Referência Geocêntrico para as Ámericas (SIRGAS 2000), com as coordenadas em Universal Transversa de Mercator - UTM na Zona 21 S.

A metodologia utilizada nesse processo de delimitação subdividiu-se em seis etapas: preenchimento de depressões (fillsinks), direção do fluxo (FlowDirection), fluxo acumulado (FlowAccumulation), definição do corpo d'água (StreamDefinition), divisão dos corpos d'água (StreamSegmentation) e delimitação da bacia hidrográfica (WatershedDelineation). Os contornos das bacias foram suavizados em 100 metros com a ferramenta SmoothPolygon localizada em ArcToolbox - Cartography Tools - Generalization - SmoothPolygon. Com os polígonos processados, foi possível a obtenção dos valores de áreas, perímetro e extensão dos corpos d'água utilizando a calculadora geométrica do software ArcGIS ${ }^{\circledR} 10.5$.

Após a obtenção dos limites das bacias, procedeu-se ao pré-processamento dos dados digitais de declividade na plataforma ArcMap, elevação e drenagem. Por meio ferramentaSpatialAnalyst Tools - Surface, foi possível gerar o mapa de declividade utilizando a ferramenta Slopee também as curvas de nível com 10 metros de distância utilizado a ferramenta Contour. A declividade das bacias foi gerada em percentual e as classes de declividade foram separadas em seis intervalos distintos, sugeridos pelas Embrapa (2006).

\begin{tabular}{cc} 
Tabela 1 - Classificação da declividade segundo a EMBRAPA (2006) \\
\hline Declividade $(\boldsymbol{\%})$ & Discriminação \\
$0-3$ & Relevo Plano \\
$3-8$ & Relevo Suavemente Ondulado \\
$8-20$ & Relevo Ondulado \\
$20-45$ & Relevo Fortemente Ondulado \\
$45-75$ & Relevo Montanhoso \\
$>75$ & Relevo Escarpado \\
\hline
\end{tabular}


A classificação das imagens foi executada de forma supervisionada utilizando o software eCognitonDeveloper 64, utilizando uma imagem do satélite LANDSAT 8, cuja a banda 223 e ponto 071 compreendia toda a área a ser explorada, portanto, não houve necessidade de elaborar um mosaico com outras bandas. O processo de classificação se deu primeiramente na escolha das classes, sendo elas: vegetação densa (arvores com copas), vegetação rasteira (tipo savana), solo exposto, massa d'água (lagoas e outras formas de represamento), hidrografia (rios e córregos) e área urbana.

O software eCognition possibilita a segmentação da imagem, isso faz com que a imagem seja fracionada em um conjunto de pixels e com analise visual da imagem da área estudada é possível identificar o tipo de uso e ocupação existente por meio da calibragem do RGB 654. Dessa forma é possível realizar o processo de vetorização das imagens, classificando-as conforme o objetivo do trabalho de forma que e seja condizente com o contexto local.

\subsection{Determinação das características fisiográficos}

De posse da delimitação da área da bacia, obtiveram-se as seguintes características físicas: fator forma, área da bacia, perímetro, coeficiente de compacidade, fator de forma, índice de circularidade, declividade, altitude, densidade de drenagem e ordem dos cursos d'água.

\subsubsection{Fator forma $(\mathrm{Kf})$}

Relaciona a forma da bacia com a de um retângulo, correspondendo à razão entre a largura média e o comprimento axial da bacia (Equação 1), sendo o F: o fator de forma, A: a área de drenagem $\left(\mathrm{em} \mathrm{m}^{2}\right)$ e L: o comprimento do eixo da bacia (em $\left.\mathrm{m}\right)$.

$K f=\frac{A}{L^{2}}$

\subsubsection{Coeficiente de compacidade $(K c)$}

É a relação entre o perímetro e a circunferência da bacia com um círculo (Equação 2), sendo: Kc: o coeficiente de compacidade, P: o perímetro $(\mathrm{m})$ e A: área de drenagem $\left(\mathrm{m}^{2}\right)$. Segundo a classificação de Oliveira (1997), valores de $\mathrm{Kc}<1,2$ (área totalmente sujeita a enchente), valores de Kc entre 1,2 a 1,5 (área parcialmente sujeita a enchentes) e Kc>1,5 (área não sujeita a enchentes).

$K c=0,28 \frac{P}{\sqrt{A}}$

\subsection{3 Índice de Circularidade (IC)}

Assim como o coeficiente de compacidade, o índice de circularidade (IC) tende para a medida da bacia, mas conforme a forma da bacia se alonga, o valor diminui. É calculado pela relação entre A e P (Equação 3), sendo A: área de drenagem ( $\left.\mathrm{em} \mathrm{m}^{2}\right)$ e P: o perímetro (em m). Segundo Muller (1953), o IC pode ser classificado de três maneiras: valores < 0,51 demonstram que a bacia tende a ser mais alongada e tem como tendência o favorecimento do escoamento; $=0,51$ demonstra um nível moderado de escoamento e valores $>0,51$ apresentam forte indício de que a bacia tende a um formato circular, o que favorece os processos de enchentes 
MORAES, GABRIEL; et al; Caracterização Fisiográfica e do uso e Ocupação do Solo das Microbacias Urbanas da Cidade de Cuiabá-MT. E\&S Engineering and Science, (2018), 7:2.

$I c=\frac{12,57 x A}{P^{2}}$

\subsubsection{Densidade de drenagem}

A densidade de drenagem indica a velocidade com que a água deixa a bacia hidrográfica, sendo assim, o índice indica o grau de desenvolvimento do sistema de drenagem, indicando a eficiência da drenagem. $\mathrm{O}$ cálculo se dá por meio da divisão do Lt: comprimento total dos rios da bacia, sejam eles perenes ou intermitentes; e por A: área total da bacia, cuja a unidade de medida se dá por $\mathrm{Km} / \mathrm{Km}^{2}$ (Equação 4).

$D d=\frac{L t}{A}$

\subsubsection{Extensão média do escoamento superficial}

O parâmetro de extensão média do escoamento superficial aponta a distância média que a água precipitada teria que escoar sobre uma bacia, em linha reta, do local onde ocorre sua queda, até um local mais próximo no leito de curso d'água (VILELLA e MATTOS, 1975) (Equação 5).

$l=\frac{A}{4 x L}$

\subsubsection{Ordem}

Utilizou-se neste trabalho a classificação proposta por Strahler (1957), em que os canais sem tributários são designados de primeira ordem. Os canais de segunda ordem são os que se originam da confluência de dois canais de primeira ordem, podendo ter afluentes também de primeira ordem. Os canais de terceira ordem originam-se da confluência de dois canais de segunda ordem, podendo receber afluentes de segunda e primeiras ordens, e assim sucessivamente (SOUZA et al., 2013).

\section{RESULTADOS}

\subsection{Hidrografia}

Os resultados obtidos das características fisiográficas das oito Bacias Hidrográficas supracitadas (Tabela 2), classificou a Bacia do Rio Coxipó como sendo uma bacia de $5^{\text {a }}$ ordem e a Bacia do Ribeirão do Lipa como sendo uma microbacia de $3^{\mathrm{a}}$ ordem, as demais bacias foram classificadas como bacias de $2^{\mathrm{a}}$ ordem.

Os coeficientes de compacidade Kc das Bacias do Córrego Mané Pinto e do Córrego do Gambá resultaram em 1,24 e 1,48, respectivamente, o que configura em áreas com maior probabilidade de enchente e as demais bacias obtiveram um valor de $\mathrm{Kc}$ acima de 1,5 caracterizando uma área não sujeita a enchentes.

Os índices de circularidade das bacias apresentaram um valor menor que 0,51, pois são bacias com formato alongados, o que favorece o escoamento superficial, complementando o diagnóstico parcial indicado pelo Kc, com exceção da bacia do Mané Pinto, que apresentou um IC de 0,64 , caracterizando um formato circular favorecendo os processos de enchentes.

$\mathrm{O}$ fator forma $\mathrm{Kf}$ determinado corrobora para tal afirmação sobre o $\mathrm{Kc}$, pois os valores obtidos foram baixos. Segundo Villela e Matos (1975) indica que um valor baixo para o fator 
MORAES, GABRIEL; et al; Caracterização Fisiográfica e do uso e Ocupação do Solo das Microbacias Urbanas da Cidade de Cuiabá-MT. E\&S Engineering and Science, (2018), 7:2.

forma indica menor tendência para a enchentes. Quanto menor o Kf, mais comprida é a bacia e, portanto, menos sujeita a picos de enchente.

Tabela 2 - Resultados das análises fisiográficas da microbacias

\begin{tabular}{|c|c|c|c|c|c|c|c|c|c|}
\hline Bacias & $\begin{array}{l}\text { Área de } \\
\text { Drenagem } \\
\left(\mathrm{Km}^{2}\right)\end{array}$ & $\begin{array}{l}\text { Perímetro } \\
(\mathrm{Km})\end{array}$ & $\begin{array}{c}\text { Extensão } \\
\text { do Eixo } \\
\text { Principal } \\
(\mathrm{Km})\end{array}$ & $\begin{array}{l}\text { Fator } \\
\text { Forma } \\
\text { (Kf) }\end{array}$ & $\begin{array}{c}\text { Coeficiente } \\
\text { Compacidade } \\
\text { (Kc) }\end{array}$ & $\begin{array}{l}\text { Índice de } \\
\text { Circularidade } \\
\text { (Ic) }\end{array}$ & $\begin{array}{l}\text { Densidade } \\
\text { Drenagem } \\
\text { (Dd) }\end{array}$ & $\begin{array}{l}\text { Sistema } \\
\text { Drenagem } \\
\text { (Rd) }\end{array}$ & Ordem \\
\hline $\begin{array}{l}\text { Ribeirão do } \\
\text { Lipa }\end{array}$ & 64,43 & 46,99 & 17,79 & 0,20 & 1,64 & 0,37 & 1,45 & 93,23 & $3^{a}$ \\
\hline Mané Pinto & 6,73 & 11,52 & 3,31 & 0,62 & 1,24 & 0,64 & 0,58 & 3,92 & $2^{a}$ \\
\hline Prainha & 5,40 & 12,82 & 4,38 & 0,28 & 1,55 & 0,41 & 0,92 & 4,97 & $2^{a}$ \\
\hline $\begin{array}{l}\text { Córrego do } \\
\text { Gambá }\end{array}$ & 5,07 & 11,92 & 4,11 & 0,30 & 1,48 & 0,45 & 1,11 & 5,62 & $2^{a}$ \\
\hline $\begin{array}{c}\text { Córrego do } \\
\text { Barbado }\end{array}$ & 14,25 & 24,30 & 8,90 & 0,18 & 1,80 & 0,30 & 0,62 & 8,90 & $2^{a}$ \\
\hline Rio Coxipó & 691,03 & 186,46 & 84,92 & 0,10 & 1,99 & 0,25 & 0,80 & 551,01 & $5^{a}$ \\
\hline $\begin{array}{l}\text { Córrego São } \\
\text { Gonçalo }\end{array}$ & 18,12 & 27,73 & 7,66 & 0,31 & 1,82 & 0,30 & 0,77 & 13,93 & $2^{a}$ \\
\hline $\begin{array}{l}\text { Córrego } \\
\text { Lavrinha }\end{array}$ & 4,12 & 11,90 & 4,08 & 0,25 & 1,64 & 0,37 & 1,51 & 6,20 & $2^{a}$ \\
\hline
\end{tabular}

Fonte: Os autores

A densidade de drenagem hídrica seguindo classificação de Carvalho e Silva (2018) foi considerada regular, ou seja, entre 0,5 e $1,5 \mathrm{Km} / \mathrm{Km}^{2}$. Neste caso a maior densidade de drenagem apresentada foi a do córrego Lavrinha, que apresentou um valor de 1,51 $\mathrm{Km} / \mathrm{Km}^{2}$.Isso ocorre devido a sua área ser bem menor em relação as demais bacias, quando comparadas com suas respectivas drenagens, sendo caracterizada como baixa (Figura 2). Carvalho e Silva (2018) afirma que as microbacias com baixo valor de densidade de drenagem são poucos suscetíveis a processos erosivos naturais.

Figura 2 - Hidrografia das bacias que compreende a área urbana de Cuiabá

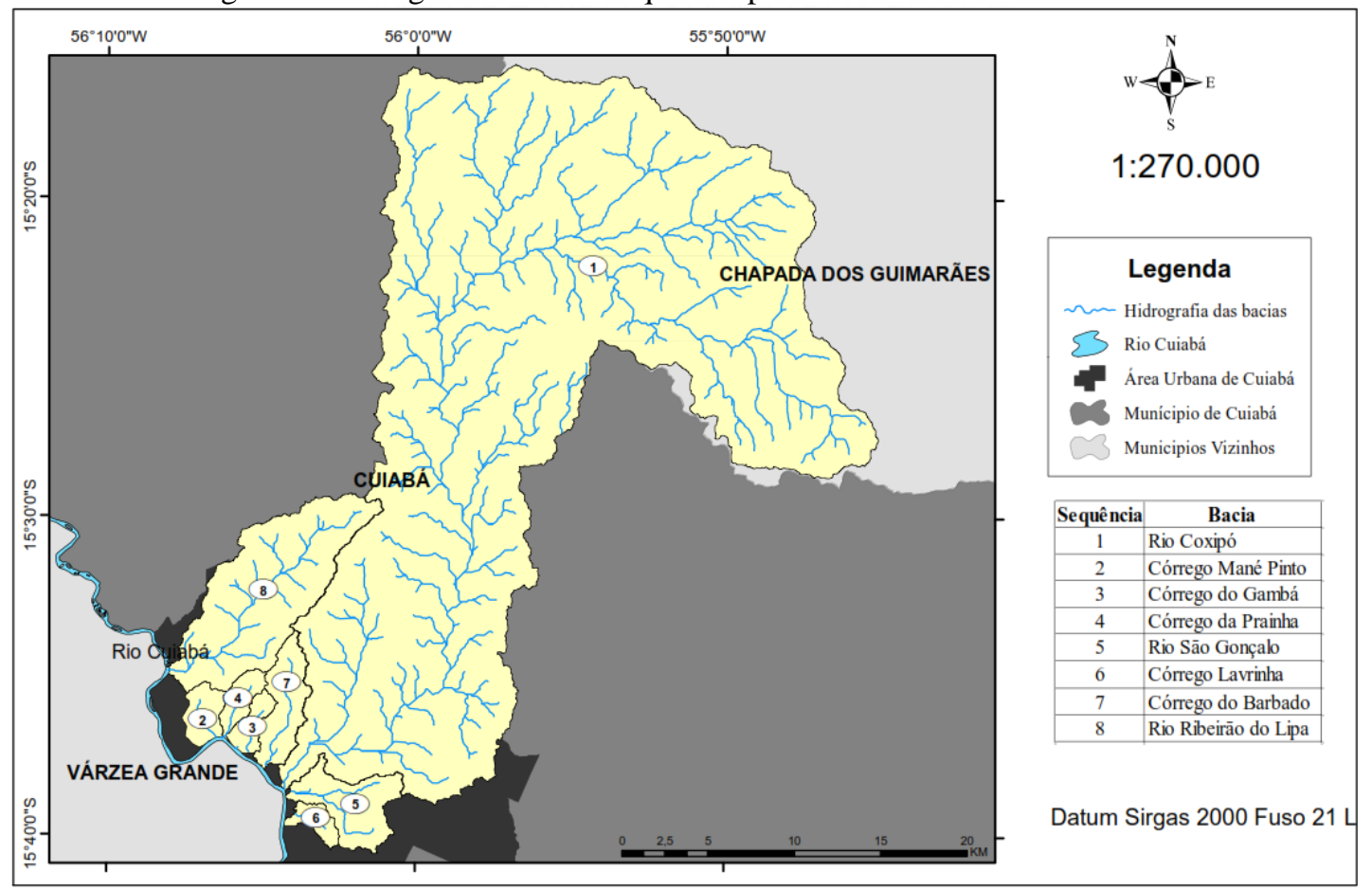

Fonte: Os autores

Com o mapa altimétrico foi possível determinara posição dos pontos situados sobre um plano de referência que se baseia em medições diretas e relacionadas com um ponto de altitude conhecida. Desta forma, o mapa altimétrico apresentado reflete as diferenças de 
altitudes das microbacias baseando-se no sistema de curvas de nível. Com o auxílio do ArcGis ${ }^{\circledR}$ foi possível obter esse resultado gerando um faixa de valores das cotas de cada plano.

Analisando a altitude da área de estudo, a variação da cota é de cota 859 metros nas partes elevadas, estando nela parte das nascentes do Rio Coxipó, até 137 metros até o exutório (Figura 3). A parte mais alta compreende a área do município de Chapada dos Guimarães, que segue de um declive bastante íngreme por causa da formação de escarpas, atenuando-se em um relevo plano com baixa inclinação até o fundo do vale.

Figura 3 - Mapa de altitude de microbacias

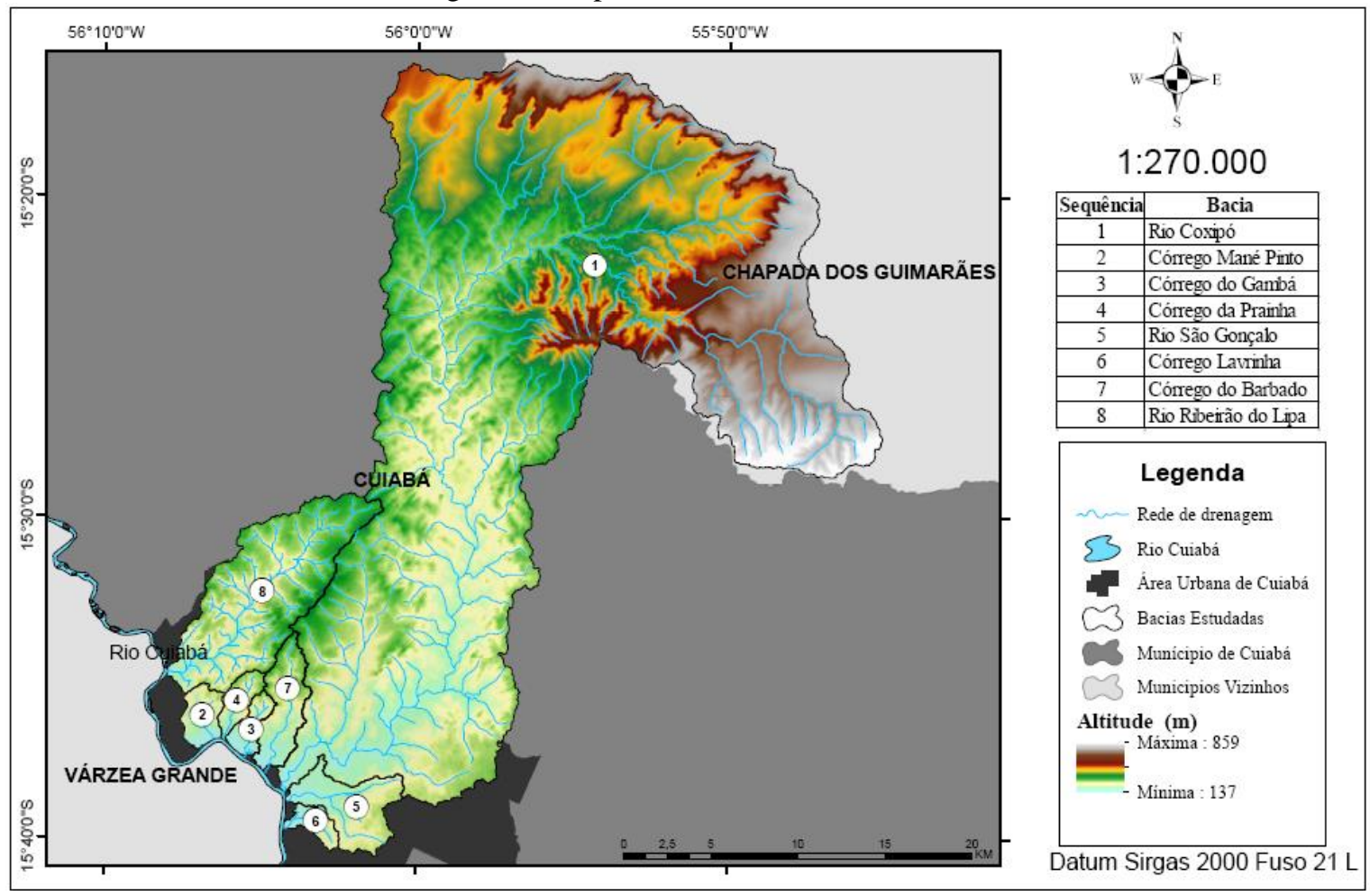

Fonte: Os autores

As declividades presentes no mapeamento preliminar são resultadas da calibragem padrão do aplicativo, as quais, posteriormente foram reclassificadas em cinco classes percentuais, conforme Embrapa (2006) em função de separação das feições do interesse para uma melhor apresentação do layout. Segundo Tucci (2012), a declividade das vertentes pode ser feita classificando diferentes faixas de valor pode-se obter um mapa temático da bacia com diversas regiões cada qual identificada por uma faixa de variação.

Apesar da grande diferença de altimetria da região analisada, a declividade (Figura 4) demonstrou que a área de estudo não propicia a ocorrência de graves processos erosivos de origem natural. Esta constatação pode verificada visto que a mesma apresenta a maior parte de sua área com relevo variando de plano ao relevo ondulado. A declividade na região plana da bacia ficou entre 0\% a 7,3\%, declividade considerada baixa. Esta característica contribui para que o tempo de concentração dos processos erosivos aumente (Figura 4).

Para a facilitar a visualização e compreensão, as cores frias (tons esverdeados) foram escolhidas para representar as áreas planas e as cores quentes (amarelo, laranja e vermelho) as áreas mais declivosas do terreno. As pequenas porções de áreas planas localizadas entre faixas de declínio acentuado correspondem aos fundos de vale. Há um valor discrepante entre os percentuais de declividade no mapa, pois, a altitude tem interferência direta nos resultados. A 
declividade média não pode ser contabilizada devido a indução de erro no diagnóstico da mesma. Considerou-se apenas a declividade da região planície do vale.

Figura 4 - Mapa de altitude de microbacias

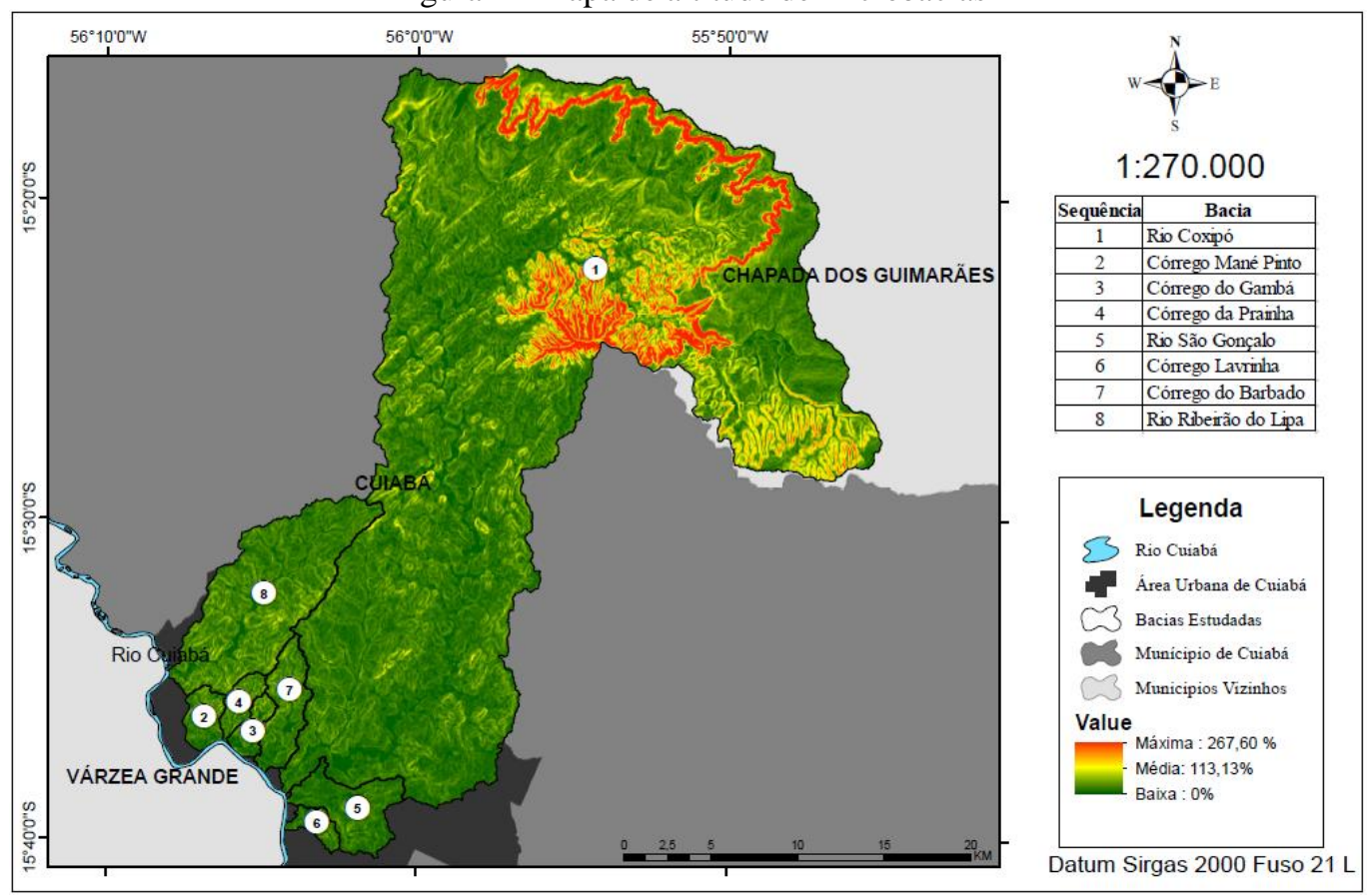

Fonte: Os autores

A vegetação densa quase não está presente nas bacias inseridas no perímetro urbano, as bacias do Córrego Mané Pinto, Prainha e Córrego do Gambá apresentaram 0\% de vegetação nativa ou densa, e inversamente, quase que proporcional, a densidade demográfica está acima de $80 \%$ relacionando com a área das bacias (Tabela 3). Contudo, observa-se que essa indicação está associada à resolução da imagem de satélite, podendo apresentar índices de vegetação maiores com a utilização de imagens com maior precisão. Nota-se que a ocupação urbana na bacia do Rio Coxipó é de 8,3\%, mas isso em relação a área da bacia, porém, esse valor refere-se a $57,30 \mathrm{Km}^{2}$ de área ocupada.

Tabela 3 - Proporção do uso e ocupação do solo nas bacias em relação a suas áreas

\begin{tabular}{ccccccc}
\hline BACIAS & $\begin{array}{c}\text { Hidrografia } \\
(\boldsymbol{\%})\end{array}$ & $\begin{array}{c}\text { Massa } \\
\text { D'água } \\
(\boldsymbol{\%})\end{array}$ & $\begin{array}{c}\text { Solo } \\
\text { Exposto } \\
\mathbf{( \% )}\end{array}$ & $\begin{array}{c}\text { Vegetação } \\
\text { Densa } \\
(\boldsymbol{\%})\end{array}$ & $\begin{array}{c}\text { Vegetação } \\
\text { Rasteira }(\boldsymbol{\%})\end{array}$ & $\begin{array}{c}\text { Zona } \\
\text { Urbana } \\
(\boldsymbol{\%})\end{array}$ \\
\hline Ribeirão do Lipa & 1,60 & 0,6 & 17,9 & 9,1 & 40,2 & 30,7 \\
Mané Pinto & 0,30 & 0,00 & 1,30 & 0,00 & 6,60 & 92,00 \\
$\quad$ Prainha & 1,00 & 0,00 & 1,80 & 0,00 & 11,20 & 85,80 \\
Córrego do Gamba & 0,50 & 0,10 & 3,60 & 0,00 & 5,10 & 91,00 \\
Córrego do Barbado & 0,10 & 0,20 & 1,10 & 4,30 & 14,20 & 80,00 \\
$\quad$ Rio Coxipó & 0,80 & 0,20 & 9,40 & 31,60 & 49,70 & 8,30 \\
Córrego São Gonçalo & 0,10 & 0,40 & 11,50 & 8,10 & 28,50 & 51,60 \\
Córrego Lavrinha & 0,00 & 0,50 & 27,40 & 10,70 & 19,10 & 42,00 \\
\hline
\end{tabular}

Fonte: Os autores

No córrego do Barbado ainda há resquícios de vegetação nativa no entorno do seu leito, porém, a área em que ele se localiza é uma área de alto valor agregado devido a algumas instalações comerciais, e por possuir empreendimentos residenciais em fase de construção, comprometendo a vegetação. A bacia do Ribeirão do Lipa está passando por mudança em seu relevo por causa da constante ocupação que está se instalando na sua área, mas ela ainda 
apresenta um percentual de 40,2 \% de vegetação rasteira enquanto que a ocupação urbana ainda está em 30,7\%, mas está em fase de expansão (Figura 5).

Figura 5 - Mapa de uso e ocupação do solo

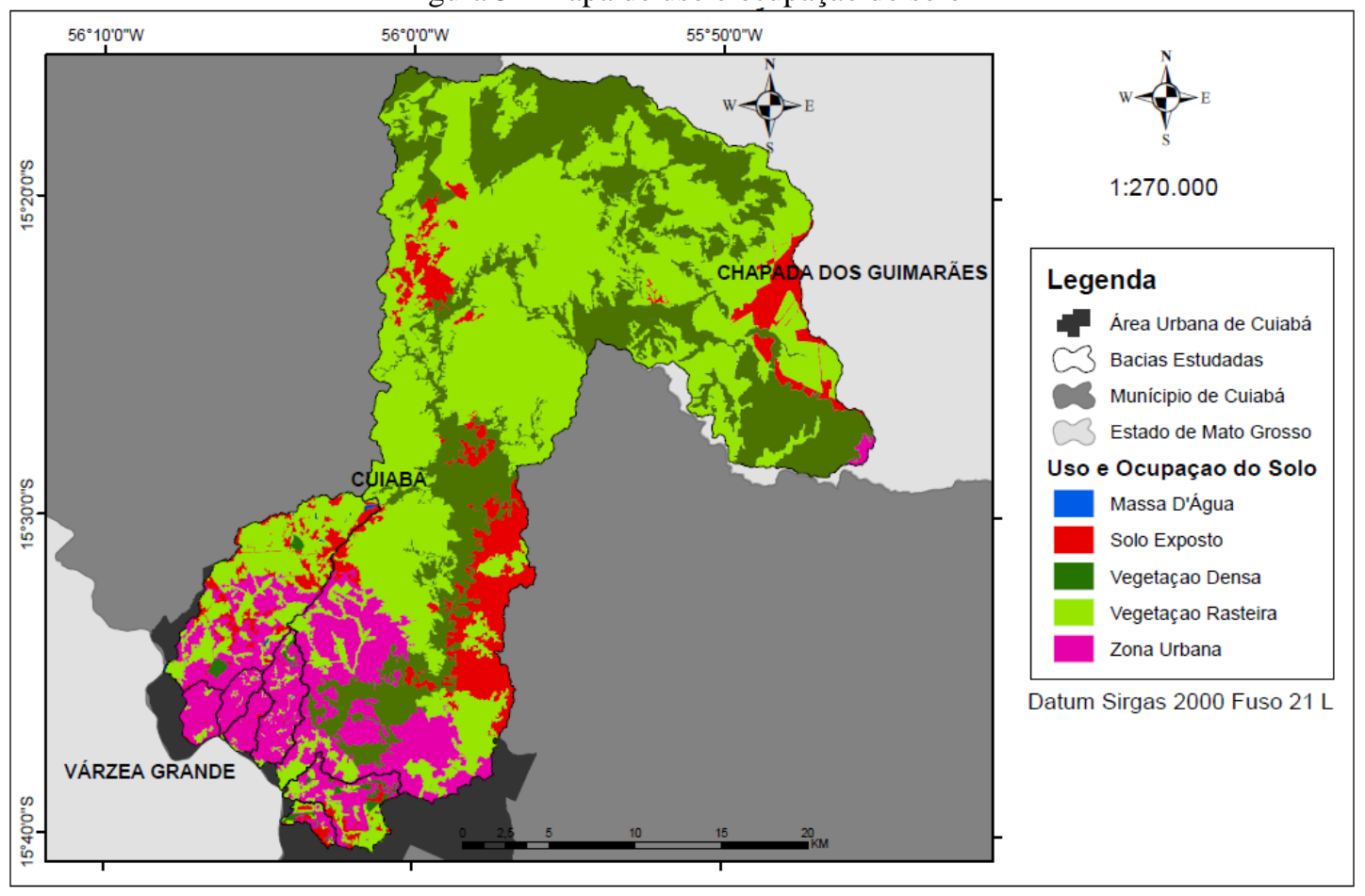

Fonte: Os autores

Por meio do mapa apresentado na Figura 5 não é possível evidenciar as massas d'água devido a escala do mesmo, mas no entorno das bacias há uma grande incidência de atividade de piscicultura e presença de pequenos reservatórios ou açudes utilizados para a dessedentação de animais das pequenas propriedades rurais, o que levou a gerar uma pequena parcela do uso e ocupação dessas áreas, não ultrapassando 0,6\% da área das microbacias.

\section{CONCLUSÃO}

Diante dos resultados obtidos, a microbacia do Córrego Mané Pinto apresenta os maiores valores de fator forma $(0,62)$ e índice de circularidade $(0,64)$, enquanto que a microbacia do Rio Coxipó tem os menores valores, sendo 0,10 e 0,25, respectivamente, assim, nota-se que a primeira é caracterizada como de maior probabilidade riscos de enchentes. Com relação ao coeficiente de compacidade, a microbacia do Córrego Mané Pinto tem o menor valor $(1,24)$, sendo considerada uma área totalmente sujeita a enchentes, enquanto que a microbacia do Rio Coxipó, com índice de 1,99, fica caracterizada como uma área não sujeita a enchentes.

O Rio Coxipó, caracterizou-se como uma bacia de $5^{\circ}$ ordem, apresentando uma ramificação significativa e densidade de drenagem regular, caracterizando probabilidade baixa a processos erosivos. As bacias da Prainha, Córrego do Gambá, Córrego do Barbado, Córrego São Gonçalo e Córrego Lavrinha, caracterizou-se como uma bacia de $2^{\circ}$ ordem, os quais originam-se da confluência de dois canais de $1^{\circ}$ ordem.

Das oito microbacias estudadas, as Mané Pinto, Prainha, Córrego do Gamba e Córrego do Barbado apresentaram uma faixa densa de ocupação urbana entre 80 a $92 \%$ do total da sua área desde a nascente até a foz. Essas bacias possuem ausência quase que total da mata ciliar, 
MORAES, GABRIEL; et al; Caracterização Fisiográfica e do uso e Ocupação do Solo das Microbacias Urbanas da Cidade de Cuiabá-MT. E\&S Engineering and Science, (2018), 7:2.

com apenas 6,6\%, 11,2\% 5,1\% e 14,2\%, respectivamente. Já as bacias Ribeirão do Lipa e do Rio Coxipó apresentam valores acima de $40 \%$ de vegetação rasteira.

\section{REFERÊNCIAS}

BRASIL. Ministério do Meio Ambiente dos Recursos Hídricos e da Amazônia Legal. Lei n. 9.433: Política Nacional de Recursos Hídricos. Brasília: Secretaria de Recursos Hídricos, 1997.

BRASIL. Instituto Nacional de Pesquisas Espaciais (INPE). Topodata: banco de dados geomorfométricos do Brasil. Disponível em: <http://www.dsr.inpe.br/topodata/>. Acesso em: 14 de junho de 2018.

CARVAlHO, D. F.; SILVA, L. D. B. Hidrologia - Capítulo 3: Bacia Hidrográfica. Disponível

em:http://www.ufrrj.br/institutos/it/deng/leonardo/downloads/APOSTILA/HIDRO-Cap3BH.pdf. Acesso em: 14 de junho de 2018.

COLET, K. M. Avaliação do impacto da urbanização sobre o escoamento superficial na bacia do Córrego do Barbado, Cuiabá-MT. 2012. 134p. Dissertação (Mestrado) Programa de Pós-Graduação em Engenharia de Edificações e Ambiental, Universidade Federal de Mato Grosso, Cuiabá-MT, 2012.

EMBRAPA. Centro Nacional de Pesquisa de Solos. Sistema brasileiro de classificação de solos. 2. ed. Rio de Janeiro: EMBRAPA-SPI, 2006.

GUERRA, A. J. T.; GONÇALVES, L. F. H. Impactos Ambientais Urbanos no Brasil. Rio de janeiro: Bertrand Brasil, 2001, 416p.

HONDA, S. C. A. L.;VIEIRA, M. C.; ALBANO, M.P. ;MARIA, Y. R. Planejamento ambiental e ocupação do solo urbano em Presidente Prudente (SP). Revista Brasileira de Gestão Urbana, v.7(1), p.62-73, 2015. DOI: 10.1590/ 2175-3369.007.001.AO04

LIMA, C. R. N. Variabilidade espacial de parâmetros de qualidade de água nas bacias do rio Cuiabá e São Lourenço. 2013.86p. Dissertação (Mestrado) - Programa de PósGraduação em Recursos Hídricos, Universidade Federal de Mato Grosso, Cuiabá-MT, 2013.

MEDEIROS, R. B.; SÃO MIGUEL, A. E.; BRUGNOLLI, C. A. C. Caracterização fisiográfica da bacia hidrográfica do Córrego das Marrecas, Dracena/SP. In: X Fórum Ambiental da Alta Paulista, v. 10, n. 2, p. 41-56, 2014.

MOREIRA, M. C.; SILVA, D. D. Atlas Hidrológico da Bacia Hidrográfica do Rio Grande. Santa Cruz do Sul: Gazeta Santa Cruz, 2010.

MOTA, S. Gestão Ambiental de Recursos Hídricos. 3ª ed. Rio de Janeiro: ABES, 2008.

MULLER, G. Methods in Sedimentary Petrology. New York: Stuttgart, 1953.

OLIVEIRA, J.N. Classificação de características fisiográficas. Texto básico para a disciplina "Hidrologia Básica". Ilha Solteira, SP: UNESP. 1997. 
MORAES, GABRIEL; et al; Caracterização Fisiográfica e do uso e Ocupação do Solo das Microbacias Urbanas da Cidade de Cuiabá-MT. E\&S Engineering and Science, (2018), 7:2.

PRADO, R. B.; NOVO, E. M. L. M.; FERREIRA, C. G. Mapeamento e caracterização dos fatores fisiográficos da bacia hidrográfica de contribuição para o reservatório de barra bonita - SP. Revista Caminhos de Geografia, v. 11, n. 36, p. 237-247, 2010.

SOUZA, H. B. S.; MACEDO, F. L.; ROMERO, C. W. S.; SIVA, H. R.; MARQUES, A. P.; PALLA, G. O.; CÉZAR, F. R. G. Análise fisiográfica da Microbacia Hidrográfica Dois Córregos, Selvíria - MS, Brasil. In: Anais XVI Simpósio Brasileiro de Sensoriamento Remoto - SBSR, Foz do Iguaçu, PR, Brasil, 2013.

STRAHLER, A.N. Quantitative analysis of watershed geomorphology. Trans. American Geophysical Union, 38: 913-920. 1957.

TUCCI, C.E.M. Inundações Urbanas. Porto Alegre: ABRHG/RHAMA, 2007. 393 p.

TUCCI, C.E. HIDROLOGIA - Ciência e Aplicação. Quarta Edição ed. Porto Alegre, RS, Brasil: UFRGS Editora.2012.

VAEZA, R. F.; OLIVEIRA FILHO, P.C.; MAIA, A.G.; DISPERATI, A. A. Uso e Ocupação do Solo em Bacia Hidrográfica Urbana a Partir de Imagens Orbitais de Alta Resolução. Floresta e Ambiente, v.17, n.1, p. 23-29, 2010. DOI 10.4322/floram.2011.003

VILLELA, S.M.; MATOS, A. Hidrologia Aplicada. São Paulo: McGraw-Hill. 1975. 